\title{
Practical subjects in the vocational curriculum: A critical review of the literature
}

\section{Christine Winberg}

Professional Education Research Unit, Cape Peninsula University of Technology, Cape Town, South Africa winbergc@cput.ac.za

https://orcid.org/0000-0001-6234-7358

\section{Shairn Hollis-Turner}

Professional Education Research Unit, Cape Peninsula University of Technology, Cape Town, South Africa Hollis-TurnerS@cput.ac.za

https://orcid.org/0000-0002-0001-3229

(Received: 5 September 2020; accepted: 14 September 2021)

\section{Abstract}

There is a growing number of studies in the field of vocational education and training, but not many focus on the practical subjects that prepare students for transition to workplaces. This critical review of the literature on practical subjects in vocational colleges set out to contribute to debates on the relationship between theory and practice in vocational education through a particular focus on the knowledge forms that are evident in curricular and pedagogical practices in practical subjects. The critical review identified the conceptual, procedural, technical, and contextual forms of knowledge in practical tasks and activities. Based on these findings and drawing on the concept of semantic gravity in Legitimation Code Theory, we found stronger and weaker forms of semantic gravity in practical knowledge and propose that strengthening and weakening semantic gravity through the purposeful selection and sequencing of tasks and activities enables cumulative knowledge building towards competent practice.

Keywords: practical subjects; vocational education; vocational colleges; critical review of the literature, semantic gravity

\section{Introduction: An overview of key debates in vocational education}

Scholars in the field agree that vocational education should support students' transitions from education to work (e.g., Allais \& Shalem, 2018; Billett, 2011; Rauner et al., 2012; Winch, 2013). However, the purposes, curricula, and pedagogies of vocational education are strongly contested. Is the purpose of vocational education to prepare young people for specific jobs or 
is it to prepare them more broadly for employability and citizenship? Educationalists have argued that vocational qualifications "have been robbed of their educational integrity and are too narrow, too task focused and too tied to particular jobs" (Wheelahan, 2015, p. 127), while industry representatives argue that vocational qualifications should meet the needs of employers and provide the basis for a skilled workforce and occupational progression as Rageth and Renold (2020) have noted.

There is, therefore, an inevitable tension in vocational curricula between the logic of education and the logic of industry. This tension is evident in the connection (or disconnection) between theory (in the form of academic subjects) and practice (in the form of practical subjects and work-based learning). Ryle (2009) proposed a distinction between know-how, or practical knowledge, and knowing that, or propositional or theoretical knowledge that has been useful in identifying a knowledge base for vocational education. Winch (2013) expanded on Ryle's distinction by pointing to the importance of the interrelationship of "knowing how and knowing that" (p. 281) in vocational curricula and warned of the consequences of neglecting this relationship. That attention has not been paid to the relationship between theoretical and practical knowledge is evident in the ongoing debates about the extent to which the curriculum should be structured by disciplinary knowledge or by occupational standards. Should the focus be on the "specifics of the vocational area with minimal curriculum extension and enrichment" (Fuller, 2015, p. 232) or should the vocational curriculum include a wider range of academic subjects and civic education? On the one hand, it is argued that theoretical subjects provide the explanatory logic and the principles that underpin practice (Wheelahan, 2015), and, on the other, that practical subjects and work-based learning provide context and opportunities to connect theory to practice (Billett, 2011). The issue of the relationship between both forms, is, however, under-represented (Winch, 2013). Geographically, there are differences across vocational education systems, with Germany, Austria, and Switzerland tending towards a broader educational base (Rauner et al., 2012), and the UK (Fuller, 2015), Australia (Wheelahan, 2015) and many developing countries tending towards a more narrowly defined vocational curriculum (McGrath et al., 2020).

Whether or not a vocational pedagogy exists is debatable, given the varied terrain of vocational education. The classic so-called signature pedagogy of vocational training was apprenticeship, but with the shift towards college-based vocational education (dating back to the early 20th century), scholars identified a disjuncture between the goals of vocational education and the pedagogies most effective for the achievement of those goals (Lucas, 2014). Rauner et al. (2012) proposed that a vocational pedagogy has to address both propositional and procedural knowledge, i.e., not only how to perform an action but "why it is shaped this way rather than another and how the processes of genesis and design take place as part of the development of society" (p. 20). Indeed, studies show that that narrow outcomes "have long been identified as only accounting for superficial learning" rather than "complex performance" (Billet, 2011, p. 7). "Competence", interpreted as the "professional competence to act", plays a major part in the debates in vocational pedagogy and especially in the system of examinations (Rauner et al., 2012, p. 20). Thus, the ways in which vocational 
courses are assessed, and the role of academic staff and practitioners in assessment "has to be viewed as a dimension of the development of professional competence, and to be integrated into a model of competence development" (Rauner et al., 2012, p. 32).

There are related debates about the settings in which vocational education should take place. Should students be primarily located in the workplace with some classroom provision or should it be the other way around with full-time attendance at a vocational college and some opportunities for workplace experience? Billett (2011, p. 17) warned of "the cognitive consequences of participating in an environment that is remote from those in which the knowledge to be learned is applied." Clearly, colleges are "not able to provide the full range of authentic experiences required" for competent practice (p. 125), and practical subjects cannot take the place of internships and other forms of work-based learning. In this regard, practical subjects and students' engagement in practical activities while undertaking vocational studies in colleges is understood not as a substitute for actual work experience, but as a preparation for work placement (Rauner et al., 2012).

The extent to which practical subjects support successful transition into workplaces and competence-building is the focus of this critical review. In the context of practical training, Winch pointed to the importance of mapping "the main kinds of know-how that need to be taken account of" in preparing students for practice (2013, pp. 281-282). While there has been "an exponential increase in articles with a vocational focus" (Gessler \& Siemer, 2020), very few of these studies have a focus on practical vocational subjects. It is thus timely that a critical review of the literature on practical subjects be undertaken to address "the need for review studies for the purposes of systematic knowledge aggregation, clarification and interpretation" (p. 100). The research question guiding this critical review of the literature is: "How do curricular and pedagogical arrangements in practical vocational subjects support students' transitions to work?" Our intention in this study is to contribute to debates on the relationship between theory and practice in vocational education through a particular focus on the knowledge forms that are evident in curricular and pedagogical practices in practical subjects.

\section{A theoretical framework for critically reviewing the literature on practical vocational subjects}

Because the focus of the critical review is on the knowledge forms that are evident in curricula and pedagogies in practical vocational subjects, we conceptually framed the critical review with Legitimation Code Theory (LCT), a social realist framework that has been widely used to study the knowledge base of different types and levels of educational provision (Maton, 2014), including vocational education (e.g., Johansson, 2020). LCT is multi-dimensional in offering a variety of concepts and tools to analyse practices. Each dimension explores one set of organising principles of dispositions, practices, and fields, conceptualised in LCT as legitimation codes. An analysis of legitimation codes explores "what is possible for whom, when, where and how, and who is able to define these possibilities, when, where and how" (Maton, 2014, p. 18). 
Analysing a field of practice involves identifying the semantic structures "whose organizing principles are conceptualized as semantic codes comprising semantic gravity and semantic density" (Maton, 2014, p. 2). Semantic gravity explains the degree of context-dependence of meaning while semantic density explains the degree of condensation of meaning (Maton, 2014). Both semantic gravity and semantic density are necessary in a vocational curriculum, and an appropriate relationship between them is key to the success of vocational programmes. A focus on semantic density would foreground the theoretical, abstract components of the programme, while a focus on semantic gravity reveals the contextual, practical, work- or occupation-oriented aspects of the programme.

Winch (2013, p. 282) pointed out that there is "an excessive concentration on skill" in the vocational literature, rather than on "other forms of know-how whose development is vital to any professional or vocational education." Consequently, there is a need "to articulate the main relationships between these different kinds of know-how." In order to define appropriate forms of know-how, as well as to explain the relations between the different forms of know-how, we drew, as mentioned above, on the concept of semantic gravity. Semantic gravity approximates to Ryle's (2009) notion of know-how and it is this practical knowledge form that is foregrounded in our study. Winch (2013, p. 283) argued that we should resist "attempts at reduction, either of know-how to knowing that (broadly speaking the intellectualist tradition) or of knowing that to know-how (what is sometimes known as 'strong anti-intellectualism')." For this critical review of the literature on practical subjects, know-how or, in this case, semantic gravity, highlights the different forms of practical knowledge and the nature of the relationships between types of semantic gravity in practical subjects that were important to preparing students for transition into work practices. While we acknowledge the presence and importance of semantic density in practical subjects, and generally in vocational curricula, the focus of this study is practical knowledge, and the relationships between forms of practical knowledge in practical subjects. The focus on semantic gravity does not imply that semantic density is absent; there is often an inverse relationship between semantic gravity and semantic density. When semantic gravity is weaker, it is less embedded in its context, thus enabling the inclusion of conceptual knowledge within practice. Because of its potential to identify relationships between theory and practice through stronger and weaker linkages to contexts, semantic gravity is pertinent to a study of knowledge in practical training.

\section{Translation Device}

In order to operationalize the concept of semantic gravity a "translation device" (Maton \& Chen, 2016, p. 28) was needed to form a bridge between the high level concept of semantic gravity and its application to studies of practical work in vocational education and training (see Table 1). 
Table 1

Translation device for semantic gravity in practical vocational subjects

\begin{tabular}{|c|c|c|c|c|}
\hline Semantic Gravity & Range & Knowledge & Codes & Descriptors/examples \\
\hline $\begin{array}{c}\text { Weaker } \\
\text { Semantic Gravity }\end{array}$ & 4 & Conceptual & SG- & $\begin{array}{l}\text { Theory, concepts, and principles } \\
\text { that underpin practice. }\end{array}$ \\
\hline $\begin{array}{l}\text { Stronger Semantic } \\
\text { Gravity }\end{array}$ & $\downarrow$ & Contextual & $\mathrm{SG}^{+}$ & Knowledge acquired in practice. \\
\hline
\end{tabular}

In practical subjects, weaker semantic gravity (SG-) indicates the foregrounding of concepts and principles, while stronger semantic gravity $\left(\mathrm{SG}^{+}\right)$is evident in contextually embedded forms of knowledge that develop through practice and that are often tacit and difficult to explain and to teach. The arrow in the Range column indicates that weaker and stronger forms of semantic gravity can be positioned along a continuum. The difference between practical work that is undertaken as part of an internship, or other form of workplace learning, and the training provided in practical subjects is the presence or absence of real work. While there are many forms of learning in practical subjects, such as active and engaged classroom learning, problem-based learning, laboratory work, studio work, and simulations, these would not be equivalent to actual workplace practice. However practical subjects are likely to have stronger semantic gravity and might adapt ideas from actual work practices. Curricular and pedagogical practices are likely to draw on a range of knowledge types, concepts, and codified forms of knowledge as well as knowledge arising from practical tasks and activities.

Winch (2013) identified three types of know-how, namely "skill (and its technique component), transversal ability and project management ability" (p. 281). He proposed a "nesting" or "hierarchical relationship" between the three forms of practical knowledge (p. 295). There are two aspects to "skill", namely "the ability to perform tasks" and the "technique" used to perform them. "Transversal abilities" include "planning, communicating, [and] evaluating," and develop from skills (pp. 287-288). Despite their name, transversal abilities are context-dependent because they arise from a particular vocational field, and while they are transferable within the vocational field, they are generally not transferable across fields. Finally, project management is an ability to put into effect "relatively long-term sequences of actions" that build on and articulate different transversal abilities (p. 821).

We used semantic gravity in the critical review to study curricular and pedagogical practices in practical subjects, determine practice variations across occupational fields, and explain the knowledge forms that underpin the practices. Traversing the full extent of the semantic gravity range has been shown to enable students to draw on theoretical concepts in order to formulate solutions to the challenges they confront in practice (Maton, 2014). The translation device (Table 1) was used to make visible the extent to which the studies focused on different forms of knowledge in practical training and provided the theoretical basis from which curricular and pedagogical practices in vocational subjects could be critically appraised. 


\section{Methodology of the critical review of the literature}

We followed the PRISMA methodology for critically reviewing the literature (Evans et al., 2012). In common with systematic reviews, for Eva $(2008$, p. 853) a critical review presents a "synthesis of a variety of literatures, identifies knowledge that is well established, highlights gaps in understanding, and provides some guidance regarding what remains to be understood." A critical review is particularly apposite when scholars hold different views, as is the case in relation to the practical training of students in vocational education. The distinctiveness of a critical review is that the results "should give a new perspective on an old problem, rather than simply paraphrasing what all other researchers and scholars in the field have shown or said in the past" (p. 853). The PRISMA critical review methodology is comprised of four steps: 1) identification of the studies through a transparent and replicable search strategy; 2) screening of the studies for duplications and for relevance to the topic; 3 ) checking the eligibility of the data extracted against justifiable quality criteria; and 4) critically analysing the data extracted (Evans et al., 2012). It is the last step, i.e., the critical analysis of the study data that distinguishes a critical review from a systematic review. In a critical review, drawing on a theoretical framework to provide new perspectives and theoretically informed insights into the studies reviewed, the data extracted is coded and thematically analysed.

\section{Identification}

The search strategy included the selection of appropriate search terms and testing them via pilot searches. The vocational education literature does not use standard terms for practical training in colleges, thus a number of context-specific terms were required (e.g., "practical training", "practical subjects", "school-to-work", "pre-apprenticeship"). Since practical training is a term commonly used for industry-based training in work placements, we excluded "industry" in the searches. When we searched in generic databases we included "vocational education", "vocational training", "VET" and "TVET" in the searches, but when we were searching in or cross-checking vocational education journals, this was unnecessary. We searched six academic databases and cross-checked in a meta-database (SCOPUPS) as well as in nine individual journals. We also searched relevant journals that were not in academic publishers' databases. Table 2 provides a schematic representation of the search strategy.

We included articles on the basis of relevance, i.e., if they were research studies on the curricula, teaching, learning, and/or assessment of practical subjects or practical training in technical and vocational colleges. The searches conducted resulted in an initial database of 256 articles, books, book chapters, and conference proceedings.

\section{Screening}

Duplicate or very similar studies were removed. Titles and abstracts were not helpful in judging the study's relevance to the topic since many terms used to describe industry or higher education training are similar to those used in college-based training. Consequently, 
we read all articles, chapters, and conference proceedings in order to determine their eligibility for inclusion in the study.

Table 2

The Search strategy

\begin{tabular}{|c|c|c|}
\hline SEARCH TERMS & $\begin{array}{l}\text { DATABASES } \\
\text { SEARCHED }\end{array}$ & CROSS-CHECKED IN \\
\hline \multirow{10}{*}{$\begin{array}{l}\text { ("Vocational Education" } \\
\text { OR "Vocational Training" } \\
\text { OR VET OR TVET) AND } \\
\text { ("practical training" OR } \\
\text { "practical subject" OR } \\
\text { "school-to-work" OR "pre- } \\
\text { apprenticeship") NOT } \\
\text { industry NOT university } \\
\text { NOT "higher vocational } \\
\text { education" }\end{array}$} & Elsevier & Journal of Vocational Behavior \\
\hline & Emerald & Education + Training \\
\hline & IEEE Xplore & IEEE Transactions on Education \\
\hline & \multirow[t]{2}{*}{ SABINET } & $\begin{array}{l}\text { Journal of Vocational, Adult and } \\
\text { Continuing Education and Training }\end{array}$ \\
\hline & & Journal of Education \\
\hline & SCOPUS & $\begin{array}{l}\text { International Journal for Research in } \\
\text { Vocational Education and Training } \\
\text { (IJRVET) }\end{array}$ \\
\hline & Springer & $\begin{array}{l}\text { Empirical Research in Vocational } \\
\text { Education and Training }\end{array}$ \\
\hline & \multirow[t]{3}{*}{ Taylor and Francis } & $\begin{array}{l}\text { Journal of Vocational Education \& } \\
\text { Training }\end{array}$ \\
\hline & & Journal of Education and Work \\
\hline & & $\begin{array}{l}\text { International Journal of Training } \\
\text { Research }\end{array}$ \\
\hline \multicolumn{3}{|c|}{ JOURNALS NOT IN ACADEMIC PUBLISHERS' DATABASES } \\
\hline \multirow[t]{2}{*}{ Search terms as above } & - & $\begin{array}{l}\text { Nordic Journal of Vocational } \\
\text { Education and Training }\end{array}$ \\
\hline & - & $\begin{array}{l}\text { Journal of Technical Education and } \\
\text { Training }\end{array}$ \\
\hline
\end{tabular}

\section{Eligibility}

Following screening, 68 studies remained in the database. We re-read all items in it and screened articles on quality criteria. The intention was to include only empirical research studies and research-based evaluation studies. Thus, articles that were position papers, reviews, opinions, shorter than two pages, or that lacked a methodology section were excluded, resulting in a final database of 63 studies. We excluded studies earlier than 2010 to keep the database as up to date as possible.

\section{Included for critical analysis}

The translation device provided the basis for an iterative process of identifying emergent themes by consensus. Finally, we produced a synthesis of the findings, paying particular attention to commonalities across studies. We used the translation device (Table 1) to code 
the data. Both of us jointly coded and analysed the studies. The literature was managed in an Excel database (available at http link).

\section{Figure 1}

PRISMA Flow Chart for the critical review of the literature Source: Evans et al. (2012).

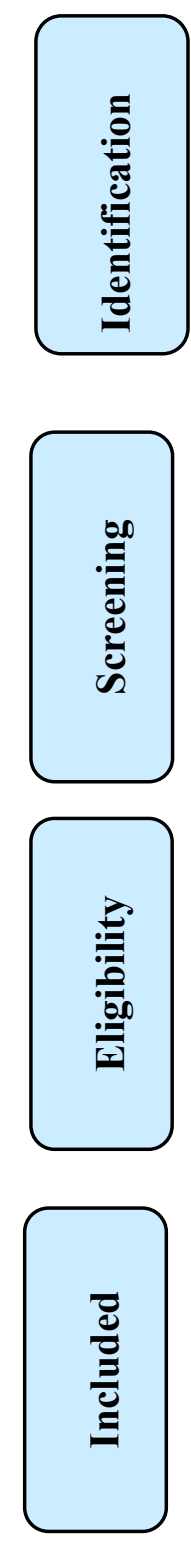

$$
\begin{aligned}
& \text { Records identified through database } \\
& \text { searches } \\
& (\mathrm{n}=234)
\end{aligned}
$$

Additional records identified through other sources $(\mathrm{n}=22)$

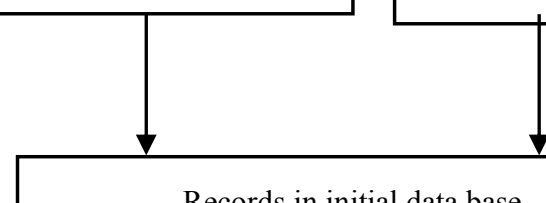

$(\mathrm{n}=256)$

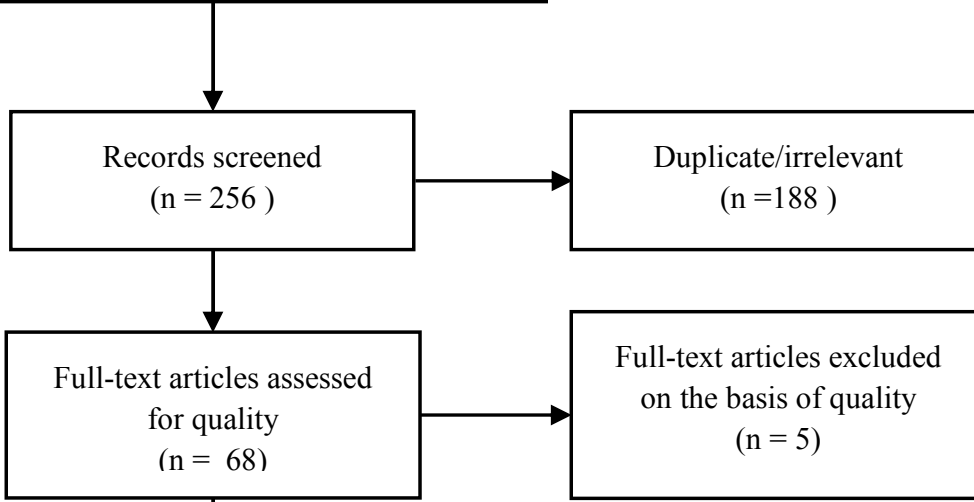

Eligible studies

$(n=63)$

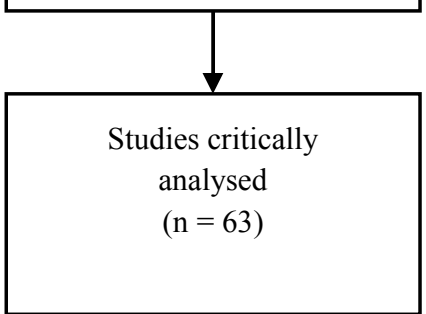




\section{Findings from the critical review of the literature}

Most of the studies (43/63) that we included in the critical review of the literature took place in European countries, with Germany, Switzerland, and the Nordic countries particularly well-represented. Asian countries, including China, India, Malaysia, and Hong Kong comprise the next cluster (11/63). We included four studies from Australia, two from the United States and three from Africa (Ghana, Nigeria, and South Africa) in the data base. The literature included a wide variety of research methods, including surveys (e.g., Chandran et al., 2018; Dasmani, 2011; Dumbrell \& Smith, 2013), observational studies (e.g., Asplund \& Kontio, 2020; Louw, 2013; Sjöberg, 2014), interview-based studies (e.g., Aakernes, 2018; Callan et al., 2015; Heusdens et al., 2018), case studies (e.g., Gleeson, 2016; Kotsifakos et al., 2018), document-based studies (e.g., Nylund \& Rosvall, 2016; Rauner et al., 2012), comparisons (e.g., Kap, 2014; Sappa et al., 2016; Schröder, 2019) and evaluations of interventions (e.g., Hoareau et al., 2017; Shrestha, 2016; Yasak \& Alias, 2017). Several studies used mixed-method approaches, such as surveys and interviews (e.g., Deitmer \& Heinemann, 2017; Stalder, 2012) and "obser-views" that combined observations with interviews (Aarkrog, 2019; Hamid et al., 2012).

\section{Conceptual underpinnings of practical subjects}

Ten studies $(16 \%)$ focused on the role of conceptual knowledge in practical subjects. Studies in this category described different ways in which connections were made between disciplinary knowledge and practical activities, particularly in laboratory-based practicals. Most studies in this category were in engineering fields, including automotive (Nylund \& Rosvall, 2016), mechanical (Kotsifakos et al., 2018), electronic (Kotsifakos et al., 2019) and software engineering (Kosmidis et al., 2019), as well as in information technology (Gkamas et al., 2019; Yasak \& Alias, 2017) and green technologies (Gleeson, 2016). The studies highlighted how scientific knowledge was drawn on in technical tasks and activities. Gleeson (2016) made a case for including scientific knowledge in the practical training of heat pump installers, explaining that errors occurred when the scientific basis of a particular practice was not clear to a technician. Scientific knowledge was similarly fundamental to laboratory-based practice as Kotsifakos et al. (2018) pointed out. They argued that professional competence in software engineering is grounded in science, technology, engineering, and mathematics (STEM) knowledge. They explained their pedagogy for "in-classroom . . . computational capabilities of the latest versions of the modern software" as attempting "through STEM to make students feel the phenomena that surround them in a holistic and interdisciplinary way rather than learning isolated segments" (p. 1). Gkamas et al. (2019) explained that teaching students to "analyse domain specific trends and present them as structured information, create code to statistically analyse data, apply data statistics and data visualization" and so on, required the "integration of data science with data practice" (p. 2). 


\section{From routine to complex processes}

Procedural knowledge, or the knowledge of how to do something, is commonly associated with practical subjects and with practical training more generally (Sappa et al., 2016). Nine studies (14\%) foregrounded procedural knowledge in fields such as ambulance and rescue services (Andersson, 2016), policing (Söderström et al., 2020) and firefighting (Holmgren et al., 2019). These are fields that place a strong focus on protocols. In some occupations a period of observation of skilful practice, followed by assisted practice, was required before students engaged in independent practice (Rantatalo et al., 2019). In college-based practical training for emergency services, procedural knowledge was often learned in simulated or virtual environments. In such environments, students were able to "virtually experience a police situation, which encourages an inquiry process helpful for interpreting information and negotiating the complexities and challenges they are faced with in the practical training" (Söderström et al. 2020, p. 13).

In a study of practical subjects in business, IT, engineering, and hospitality, it was found that sequencing episodes of practice from simple to more complex tasks, was necessary for the acquisition of specific procedures, techniques, and the development of expertise (Sappa et al., 2016). In carpentry, Louw (2013) similarly found that the sequencing of activities and tasks as well as the provision of sufficient practical exercises and repetition was needed for the honing of skills to develop competence.

Procedural knowledge was also foregrounded when the practical subject included training for particular processes, such as "a complex procedure in the biomedical domain" (Hoareau et al., 2017, p. 786), project management in structural engineering (Bünning, 2013) and construction (Deitmer \& Heinemann, 2017). A rich base of procedural knowledge was necessary in the field of caregiving, where routines were often changing and needed to be "deliberated, thoroughly examined and adapted to face new challenges" (Poortman et al., 2011, p. 268).

\section{Learning the tools of the trade}

Twelve studies (19\%) focused on the specific tools and technologies that were central to practical subjects, such as developing hand skills through the use of "SMART (Skill Mentoring and Assistance in Real Time) tools" (Akshay et al., 2012, p. 1). SMART tools are devices that provide "motion monitoring and audio-visual feedback" to assist students in the skilful use of occupational tools. The SMART device "is easily attached to any vocational tool and can guide the user to conform to specific spatiotemporal trajectories and orientation as described by template shape" (p. 1). Chandran and colleagues argued that a "haptic simulator, designed to train manual lathe operators with sophisticated skills" provided an "intensity of haptic feedback" that exceeded that of trainers providing feedback on a user hand-wheel and manual lathe (2018, p. 97). In the context of technical computer engineering, augmented reality in the college laboratory "had a positive impact on student achievement in motherboard assembly” (Sirakaya \& Kilic Cakmak, 2018, p. 13). In many cases, attaining skilful practice required a purposeful sequencing of activities and tasks, management, 
monitoring, refining, and honing before the required level of practice was attained (Louw, 2013).

Occupational technologies were foregrounded in two practical programmes in the hospitality industry, namely baking (Callan et al., 2015) and cooking (Heusdens et al., 2018). In the baking course, the curriculum was designed "around the use of the technology that . . bakers use every day" (Callan et al., 2015, p. 300). Heusdens et al. (2018) similarly structured their cooking course around "conglomerations of all kinds of knowledge required for practising" (p. 436). Additional studies pointed out that integrating occupational and educational technologies into practical subjects could support students' transition to workplaces (Enochsson et al., 2020), that could lead to "new interpretations of the expected learning outcomes ... improved course designs, tasks and tutoring approaches" (Holmgren et al., 2019, p. 82).

\section{Constructing knowledge through practice}

Most of the studies (35\%) focussed on contextual forms of knowledge that developed in practical training, particularly when there was alignment between the practical training curriculum and relevant occupational standards (Hamid et al., 2012). Practical subjects provided "the occupational orientation of the main qualification" (Kap 2014, p. 360), and when "purposefully aligned with industry standards and practices" enabled students "to construct meaningful knowledge development, skills acquisition and practical competence" (Rauner et al., 2012, p. 152). Such curricular alignment in practical subjects facilitated "school-to-work transitions, while at the same time bringing forward specific transition risks before . . . apprenticeships" (Stalder, 2012, p. 124). It was important that trainers understood the occupational standard in order to distinguish the "predominantly contextually specific applications of knowledge tied to the context rather than articulating appropriate applications of knowledge from disciplinary systems of meaning" (Heusdens et al., 2018, p. 448).

Many studies focused on curricula, in particular on the alignment of training outcomes with "industry-determined specifications of performance that set out the skills, knowledge and attitudes required to operate effectively in a specific industry or profession" (Shrestha, 2016, p. 143). When there was alignment, practical subjects could be used "as a basis for the quantitative assessment of professional competences and competence development" (Rauner et al., 2012, p. xv). Several studies explained how curricular alignment with industry standards was achieved in specific disciplines. For example, in mechanical engineering tasks are "action-oriented" and consist of distinct phases, i.e., "inform, plan, decide, implement, control, and evaluate" (Wilke \& Magenheim, 2017, p. 484). The sequencing of the tasks provided the curricular logic, while the respective demands of the phases could be supported with appropriate pedagogies, such as "3D representations . . . used to enrich the work with mechanical drawings in the planning phase" (Wilke \& Magenheim, 2017, p. 484). A curriculum in the field of caregiving was similarly guided by typical tasks, in this case, the use of simulated cases each of which had three phases: "briefing, scenario, and debriefing" (Aarkrog, 2019, p. 11). Elements of work-aligned tasks, such as fault identification, diagnosis, and remediation were key to the logic of practical curricula. For example, "the use 
of competence snippets instead of comprehensive material" was important in preparing students for Industry 4.0 (Jaschke, 2014, p. 608). "Learning hierarchy techniques" was similarly helpful in developing a practical training curriculum (Yasak \& Alias, 2017, p. 183).

Effective practical training required authentic learning tasks that addressed key vocational competencies. In media and communication, for example, the students worked on authentic media productions (Aakernes, 2018); in caregiving a key central issue was "fidelity i.e., the degree to which the scenario matches the practice it is intended to simulate" (Aarkrog, 2019, p. 11). In a study comparing the training of nurses and IT technicians, Ümarik et al. (2010) found several problems in assessment practices, including "fictitious assessment practices, low quality of training and motivation of workplace trainers, and also the lack of correspondence between the school curriculum and the competence base needed in the real workplace" (p. 145). Problem-based learning in vocational education and training (PBVET) was seen to have a positive impact on competency development in the field of building construction (Fjellström, 2015). Ogbuanya and Chukwuedo (2017) implemented "varieties of faulty mobile phones ranging from simple or budget phones to high technology phones such as smart phones" in an IT technician programme, and in some cases, "faults were deliberately induced in the phones to enable the students to acquire varieties of skills during the training sessions" (p. 103). In police education, the video recording of simulated critical incidents enabled rich learning through debriefing and reflection on practice (Sjöberg, 2014). Simulation, including 3D and animation required "instructional design of the trade specific learning and teaching materials as well as the readiness of students, teachers and workplace mentors" (Ricky \& Rechell, 2015, p. 96). Sjöberg et al. (2019) claimed that students in secondary roles also engaged in deep learning through formulating and providing "feedback to primary participants and through informal discussions and reflection processes" (p. 47). Playing secondary roles in police simulation was important in the development of observation skills (Rantatalo et al., 2019, p. 490).

\section{Generic skills that support practice}

Ten studies $(16 \%)$ focused on the need to include generic skills and abilities in practical subjects. A wide variety of concepts and terms were used to describe generic skills, including: "soft skills" (Papier, 2017, p. 45); "general skills" (Nyen \& Tønder, 2018, p. 232); "transversal skills" (Gkamas et al., p. 3); "employability skills" (Ogbuanya \& Chukwuedo, 2017, p. 88), "transfer skills" (Kilbrink et al., 2018, p. 464); "transferable skills" (Gekara \& Snell, 2018, p. 107); “collaborative work" (Andersson, 2016, p. 245); "21st century skills" (Schröder, 2019, p. 87); "social networks" (Neroorkar \& Gopinath, 2019, p. 16); "vocational identities" (Klotz et al., 2014, p. 6); the "culture of workplaces" (Ortoleva \& Bétrancour, 2016, p. 179); and "active learning" (Deitmer \& Heinemann, 2017, p. 128). Nyen and Tønder argued that "there is a need to balance general and vocational skills with vocational specialisation and to integrate school-based and workplace learning" (2018, p. 232).

Not all the generic skills discussed in the articles were of the same order; some were more basic and others considerably more complex. Some skills were linked to learning skills, for example, active learning was found to be important for students' engagement in practical 
training (Dasmani, 2011). Khaled et al. (2014) claimed that students' engagement in collegebased practical training built "technical and procedural skills, but also competencies and professional identity" (p. 475). In a technical course, teachers felt that the course was successful "not only if a student had gained an apprenticeship, but also if he or she had been rehabilitated from drug or alcohol problems or if he or she enrolled in another course" (Dumbrell \& Smith, 2013, p. 170). Asplund and Kontio (2020) argued that students' "antischool culture" could be mitigated by the introduction of "happy objects" such as smartphones into practical training since the "happy objects" contributed to a positive "future vocational identity as building and constructing workers" (p. 65). Students' dispositions towards their chosen occupation were strongly influenced by their practical learning experiences and the extent to which their experience of practical training supported their identification with the occupation.

Several studies noted the role that reflection played in practical training. Eportfolios were proposed "as a tool for mediating experiences and feedback ... targeting the learning outcomes" (Nore \& Lahn, 2014, p. 24-25). When eportfolios included "writing and peer feedback in practical training" they had the potential to "integrate the social dimension of learning" and "culture of workplaces" (Ortoleva \& Bétrancour, 2016, p. 179).

Nyen and Tønder proposed the consideration of two main dimensions when one was integrating generic skills into the vocational specialisation, namely, "the degree of shielding from demands and expectations in the world of work and the degree of relevance for the development of occupational skills" (2018, p. 239). Interpersonal and inter-professional skills were particularly important in police, ambulance, and rescue services (Andersson, 2016). Appropriate practical training could support students' emergent vocational identities (Klotz et al., 2014). There were thus advantages in integrating employability skills into the vocational specialisation to provide students with opportunities "to gradually develop a vocational identity" (Nyen \& Tønder, 2018, p. 238). Practical training that included site visits to workplaces or college visits from industry representatives became "an intermediary between the industry and the graduates [that helped] build social networks" (Neroorkar \& Gopinath, 2019, p. 16). Papier similarly found that including general skills in practical training provided "vital social capital to students who had minimal resources and networks to draw on for employment" (2017, p. 46).

\section{Discussion: Opening the black box of practical knowledge}

The studies included in the critical review showcased the range and variety of practical subjects in vocational education and the varieties of curricular and pedagogical arrangements and provided critical insights into the complexity of practical knowledge. We categorised the studies according to the relative strengths of semantic gravity evident in the practices described. We identified different types of semantic gravity in the studies, namely, conceptual, procedural, technical, and contextual knowledge forms, and generic skills. While we analysed these categories separately, most studies indicated or implied shifts between stronger to weaker forms of semantic gravity. 
Many studies referred to the conceptual underpinning of practice. Even in the most practical of activities, the semantic gravity could be reduced to provide more abstract guiding principles. For example, Ortoleva and Bétrancourt, in their study on caregiving, stated that they provided students "with solid conceptual knowledge along with substantial practical experience" (2016, p. 178). In other words, their students experienced a semantic gravity range. Some studies referred to how concepts and practice (or weaker and stronger semantic gravity) were connected in post-practical reflective learning. For example, reflecting on practice enabled students "to turn concrete experiences into relevant integrated knowledge" (Schwendimann et al., 2015, p. 367).

Studies focusing on procedural knowledge explained the concepts and principles that guide the procedures. For example, Sappa et al. (2016) explained that although procedural, technical, and conceptual knowledge were distinct forms of knowledge, they were connected in the "process of 'making sense' of the practical procedures by means of the conceptual framework ... learnt in the educational environment" (p. 295).

The need to develop both specific technical skills and concepts to attain "integrative knowledge" was a constantly "moving target" (Johansson, 2020, p. 875), and practical subjects constantly shifted between the "theoretical groundwork" and the "practical work" (Wilke \& Magenheim, 2017, p. 484). Heusdens et al. (2018) found it important to categorise the types of practical work for different occupations in the hospitality industry since each task tended to include different knowledge forms. In another example, it was found that "transfer as learning for new situations did not only occur through practising and making mistakes, but also involved how something worked, and then performing it" (Kilbrink et al., 2018, p. 464). In 2010, Masodonati and colleagues pointed out that the movement between knowledge forms did not occur only from theory to practice, but from "unstable forms of knowledge" (such as the contextual knowledge developed in practice) toward "relatively stable" forms (such as procedural or conceptual knowledge) (p. 404).

Many studies focused on the alignment of the outcomes of practical subjects with industry standards and the strengthening of the semantic gravity of practical curricula and pedagogies through industry partnerships. For example, while Gkamas et al. (2019) highlighted the importance of theoretical knowledge in their study of practical subjects in IT, they also pointed to the importance of regularly updating the practical training curriculum in collaboration with industry partners, particularly in the fast-moving world of IT. However, studies also showed that alignment with industry standards was insufficient in supporting "coherence between learning in school and learning in enterprises" (Aakernes, 2018, p. 77) because such "coherence" could be attained only through more integrative forms of knowledge building. Thus while "outcomes matter", the "technical procedures or the social and occupational environment, and qualities such as richness, complexity and specificity" were also important (Heusdens et al., 2018, p. 437). While most studies supported the integration of generic skills development in practical training, there were concerns that if practical training was "driven with the aim of fulfilling specific employer skills" occupational 
outcomes as well as "the quality, depth and breadth of transferable skills" could be compromised (Gekara \& Snell, 2018, p. 107).

\section{Synthesis}

In our synthesis of the findings of the critical review, two cross-cutting themes emerged. First, the multi-layered nature of the knowledges in practical training and, second, the shifting relationships between these knowledges in learning through practice. Studies reiterated that practical subjects were constantly shifting between knowledge forms. This can be described as "cumulative knowledge building" (Maton, 2014, p. 181), which is achieved through appropriate strengthening and weakening of semantic gravity in practical subjects. Students engaged in practical tasks could be understood to be continually crossing the boundaries between different knowledge forms such as drawing on principles and codified procedures, learning to use tools effectively, and honing their skills as they engaged in increasingly complex practices. The activities described in the studies of practical subjects included conceptualising, strategizing, planning, preparing, implementing, doing, conducting, reporting, debriefing, and reflecting. These activities required students to access the full semantic gravity range if they were to attain competence.

\section{Conclusion}

This critical review of the literature on practical training in vocational education identified the stratified knowledge base of practical subjects, and showed how conceptual, procedural, technical, and contextual forms of knowledge are connected in practical tasks and activities. All knowledge types are essential for each occupation, but their relative importance varies.

Practical tasks and activities differ across and within vocational fields. Tasks with a clearly defined objective, such as "the specification of a solution for a technical problem, require a structured and systematic approach" (Rauner et al., 2012, p. 50), thus foregrounding procedural and technical knowledge forms. When there is "an openness of objectives" and more "room to manoeuvre", such as in problem-solving "activities in diagnostic work processes, e.g., in industrial and technical occupations where error diagnosis plays an important part ... defined work steps" are less important, and theoretical knowledge is necessary to guide practice (p. 51).

The studies showed that practical subjects included a range of learning experiences and activities in which the different knowledge forms are intentionally integrated into practical tasks through specifically designed curricula and pedagogies. Cumulative knowledge building requires students' engagement in diverse episodes of practice that explicitly link the knowledge forms through strengthening and weakening the semantic gravity, thus making explicit the causal links across the different knowledge forms.

The studies showed the importance of students' engagement in authentic and relevant practical tasks to support cumulative knowledge building and enable progress towards competent performance. The studies also showed that vocational educators could facilitate 
competence development in practical subjects through appropriate concepts and strategies, guiding students in the skilful use of tools and technologies and demystifying the tacit and contextual forms of knowledge that are embedded in practice.

\section{Acknowledgement}

This project was funded by the Department of Higher Education and Training's Technical and Vocational Education and Training Directorate.

\section{References}

Aakernes, N. (2018). From school to work: Coherence between learning in school and learning in workplaces for apprentices in the media graphics programme in Norway. Nordic Journal of Vocational Education and Training, 8(1), 76-97.

Aarkrog, V. (2019). 'The mannequin is more lifelike': The significance of fidelity for students' learning in simulation-based training in the social and healthcare programmes. Nordic Journal of Vocational Education and Training, 9(2), 1-18.

Akshay, N., Deepu, S., \& Bhavani, R. R. (2012). Augmented vocational tools using real time audiovisual feedback for psychomotor skill training. Proceedings of the IEEE International Conference on Technology Enhanced Education, Kerala, IN.

Allais, S., \& Shalem, Y. (2018). Curricula, work and a more just society. In S. Allais \& Y. Shalem (Eds.), Knowledge, curriculum, and preparation for work (pp. 1-12). Brill Sense.

Andersson, A. (2016). Boundaries as mechanisms for learning in emergency exercises with students from emergency service organisations. Journal of Vocational Education \& Training, 68(2), 245-262.

Asplund, S. B., \& Kontio, J. (2020). Becoming a construction worker in the connected classroom: Opposing school work with smartphones as happy objects. Nordic Journal of Vocational Education and Training, 10(1), 65-94.

Billett, S. (2011). Vocational education: Purposes, traditions and prospects. Springer Science \& Business Media.

Bünning, F. (2013). Effects of experimental learning: Outcomes of an empirical study in the vocational field of structural engineering. International Journal of Training Research, 11(1), 44-55.

Callan, V. J., Johnston, M. A., \& Poulsen, A. L. (2015). How organisations are using blended e-learning to deliver more flexible approaches to trade training. Journal of Vocational Education \& Training, 67(3), 294-309. 
Chandran, A., Rahul, E. S., \& Rao, B. R. (2018, December). Significance of haptic feedback in learning lathe operating skills. Paper presented at the 10th IEEE International Conference on Technology for Education, Chennai, IN.

Dasmani, A. (2011). Challenges facing technical institute graduates in practical skills acquisition in the Upper East Region of Ghana. International Journal of WorkIntegrated Learning, 12(2), 67-78.

Deitmer, L., \& Heinemann, L. (2017). New teaching and learning methods in further VET for general foremen in the German construction sector. In F. Kaiser \& S. Krugmann (Eds.), Social dimension and participation in vocational education and training proceedings of the 2nd conference of Crossing Boundaries in VET (pp. 124-129). University of Rostock, DE.

Dumbrell, T., \& Smith, E. (2013). Pre-apprenticeships in Australia: Differing orientations and their policy implications. Journal of Vocational Education \& Training, 65(2), $161-176$.

Enochsson, A. B., Kilbrink, N., Andersén, A., \& Ådefors, A. (2020). Connecting school and workplace with digital technology: Teachers' experiences of gaps that can be bridged. Nordic Journal of Vocational Education and Training, 10(1), 43-64.

Eva, K.W. 2008. On the limits of systematicity. Medical Education, 42, 852-853.

Evans, N., Bausewein, C., Menaca, A., Andrew, E. V., Higginson, I. J., Harding, R., Pool, R., Geysels, M., \& project PRISMA. (2012). A critical review of advance directives in Germany: Attitudes, use and healthcare professionals' compliance. Patient Education and Counseling, 87(3), 277-288.

Fjellström, M. (2015). Project-based vocational education and training: Opportunities for teacher guidance in a Swedish upper secondary school. Journal of Vocational Education \& Training, 67(2), 187-202.

Fuller, A. 2015. Vocational Education. In J. D. Wright (Ed.), International encyclopedia of the social \& behavioral sciences (2nd ed.) (pp. 232-238).

Gekara, V., \& Snell, D. (2018). Designing and delivering skills transferability and employment mobility: The challenges of a market-driven vocational education and training system. Journal of Vocational Education \& Training, 70(1), 107-129.

Gessler, M., \& Siemer, C. (2020). Umbrella review: Methodological review of reviews published in peer-reviewed journals with a substantial focus on vocational education and training research. International Journal for Research in Vocational Education and Training, 7(1), 91-125. 
Gkamas, V., Rigou, M., Perikos, I., Gueorguiev, I., Varbanov, P., \& Todorova, C. (2019, July). Learning outcomes design for data science and Internet of Things training programs. Paper presented at the10th IEEE International Conference on Information, Intelligence, Systems and Applications, Patras, GR.

Gleeson, C. P. (2016). Residential heat pump installations: The role of vocational education and training. Building Research \& Information, 44(4), 394-406.

Hamid, W. W., Saman, M. M., \& Saud, M.S. (2012). Exploring factors influencing the transfer of training using a grounded theory study: Issues and research agenda. Procedia-Social and Behavioral Sciences, 56, 662-672.

Heusdens, W. T., Baartman, L. K., \& de Bruijn, E. (2018). Knowing everything from soup to dessert: An exploratory study to describe what characterises students' vocational knowledge. Journal of Vocational Education \& Training, 70(3), 435-454.

Hoareau, C., Querrec, R., Buche, C., \& Ganier, F. (2017). Evaluation of internal and external validity of a virtual environment for learning a long procedure. International Journal of Human-Computer Interaction, 33(10), 786-798.

Holmgren, R., Haake, U., \& Söderström, T. (2019). Firefighting training at a distance: A longitudinal study. Journal of Vocational Education \& Training, 71(1), 65-86.

Jaschke, S. (2014). Mobile learning applications for technical vocational and engineering education: The use of competence snippets in laboratory courses and industry 4.0. Paper presented at the IEEE International Conference on Interactive Collaborative Learning, Dubai, UAE.

Johansson, M. W. (2020). Tracing the moving 'target' in didaktik of vocational classroom instruction. Journal of Curriculum Studies, 52(6), 870-883.

Khaled, A., Gulikers, J., Biemans, H., van der Wel, M., \& Mulder, M. (2014). Characteristics of hands-on simulations with added value for innovative secondary and higher vocational education. Journal of Vocational Education \& Training, 66(4), 462-490.

Kap, H. (2014). Programme content orientation in vocational education and training and life chances: A comparative study. Journal of Vocational Education \& Training, 66(3), 348-364.

Kilbrink, N., Bjurulf, V., Baartman, L. K., \& de Bruijn, E. (2018). Transfer of learning in Swedish technical vocational education: student experiences in the energy and industry programmes. Journal of Vocational Education \& Training, 70(3), 455-475.

Klotz, V. K., Billett, S., \& Winther, E. (2014). Promoting workforce excellence: Formation and relevance of vocational identity for vocational educational training. Empirical Research in Vocational Education and Training, 6(1), 1-20. 
Kosmidis, I., Prekas, N., Kitsas, I., \& Kekkeris, G. (2019, September). Research on the use of software specialties in vocational education and training. Paper presented at the 4th IEEE South-East Europe Design Automation, Computer Engineering, Computer Networks and Social Media Conference, Piraeus, GR.

Kotsifakos, D., Kostis, B., \& Douligeris, C. (2018, September). A case study of a laboratory experimental process in Vocational Education Training (VET). 3rd IEEE SouthEastern European Design Automation, Computer Engineering, Computer Networks and Society Media Conference, Kastoria, GR.

Kotsifakos, D., Makropoulos, G., \& Douligeris, C. (2019). Teaching internet of things (IoT) in the electronics specialty of vocational education and training. Paper presented at the 4th IEEE South-East Europe Design Automation, Computer Engineering, Computer Networks and Social Media Conference, Piraeus, GR.

Louw, A. V. (2013). Pedagogical practices in VET: Between direct and indirect teacher approaches. Nordic Journal of Vocational Education and Training, 3(1), 1-16.

Lucas, B. (2014, April). Vocational pedagogy: What it is, why it matters and what we can do about it. UNESCO-UNEVOC e-Forum. Bonn, DE.

Masdonati, J., Lamamra, N., \& Jordan, M. (2010). Vocational education and training attrition and the school-to-work transition. Education \&Training, 52(5), 404-414.

Maton, K. (2014). Building powerful knowledge: The significance of semantic waves. In E. Rata \& B. Barrett (Eds.), Knowledge and the future of the curriculum: International studies in social realism (pp. 181-197). Palgrave Macmillan.

Maton, K., \& Chen, R. (2016). LCT in qualitative research: Creating a translation device for studying constructivist pedagogy. In K. Maton, S. Hood \& S. Shay (Eds.), Knowledge-building: Educational studies in Legitimation Code Theory (pp. 27-48). Routledge.

McGrath, S., Ramsarup, P., Zeelen, J., Wedekind, V., Allais, S., Lotz-Sisitka, H., Monk, D., Openjuru, G., \& Russon, J. A. (2020). Vocational education and training for African development: A literature review. Journal of Vocational Education \& Training, 72(4), 465-487.

Neroorkar, S., \& Gopinath, P. (2019). Impact of Industrial Training Institutes (ITIs) on the employability of graduates: A study of government ITIs in Mumbai. Journal of Vocational Education \& Training, 72(1), 23-46.

Nore, H., \& Lahn, L. C. (2014). Bridging the gap between work and education in vocational education and training: A study of Norwegian apprenticeship training offices and eportfolio systems. International Journal for Research in Vocational Education and Training, 1(1), 21-34. 
Nyen, T., \& Tønder, A. H. (2018). Development of vocational skills through integration of practical training periods in school based vocational education in Norway. In S. Choy, G. B. Wärvik \& V. Lindberg (Eds.), Integration of vocational education and training experiences: Purposes, practices and principles (pp. 227-241). Springer.

Nylund, M., \& Rosvall, P.Å. (2016). A curriculum tailored for workers? Knowledge organization and possible transitions in Swedish VET. Journal of Curriculum Studies, 48(5), 692-710.

Ogbuanya, T. C., \& Chukwuedo, S.O. (2017). Career-training mentorship intervention via the Dreyfus model: Implication for career behaviors and practical skills acquisition in vocational electronic technology. Journal of Vocational Behavior, 103, 88-105.

Ortoleva, G., \& Bétrancourt, M. (2016). Supporting productive collaboration in a computersupported instructional activity: Peer-feedback on critical incidents in health care education. Journal of Vocational Education \& Training, 68(2), 178-197.

Papier, J. (2017). Improving college-to-work transitions through enhanced training for employment. Research in Post-Compulsory Education, 22(1), 38-48.

Poortman, C. L., Illeris, K., \& Nieuwenhuis, L. (2011). Apprenticeship: from learning theory to practice. Journal of Vocational Education \& Training, 63(3), 267-287.

Rageth, L., \& Renold, U. (2020). The linkage between the education and employment systems: Ideal types of vocational education and training programs. Journal of Education Policy, 35(4), 503-528.

Rantatalo, O., Sjöberg, D., Karp, S. (2019). Supporting roles in live simulations: How observers and confederates can facilitate learning. Journal of Vocational Education \& Training, 71(3), 482-499.

Rauner, F., Heinemann, L., Maurer, A., \& Haasler, B. (2012). Competence development and assessment in TVET (COMET): Theoretical framework and empirical results. Springer Science \& Business Media.

Ricky, Y. N., \& Rechell, L. (2015, December) Using mobile and flexible technologies to enable, engage and enhance learning in Vocational Education and Training (VET). Paper presented at the IEEE International Conference on Teaching, Assessment, and Learning for Engineering, Zhuhai, CN.

Ryle, G. (2009). The concept of mind. Routledge

Sappa, V., Choy, S., \& Aprea, C. (2016). Stakeholders' conceptions of connecting learning at different sites in two national VET systems. Journal of Vocational Education \& Training, 68(3), 283-301. 
Schröder, T. (2019). A regional approach for the development of TVET systems in the light of the 4th industrial revolution: The regional association of vocational and technical education in Asia. International Journal of Training Research, 17(1), 83-95.

Schwendimann, B. A., Cattaneo, A. A., Dehler Zufferey, J., Gurtner, J. L., Bétrancourt, M., \& Dillenbourg, P. (2015). The 'Erfahrraum': A pedagogical model for designing educational technologies in dual vocational systems. Journal of Vocational Education \& Training, 67(3), 367-396.

Shrestha, B. R. P. (2016). Vocational education and training graduates: Challenges in practical skills to the job market. International Journal of Social Sciences and Management, 3(3), 141-145.

Sirakaya, M., \& Kilic Cakmak, E. (2018). Effects of augmented reality on student achievement and self-efficacy in vocational education and training. International Journal for Research in Vocational Education and Training, 5(1), 1-18.

Sjöberg, D. (2014). Why don't they catch the baby? A study of a simulation of a critical incident in police education. Journal of Vocational Education \& Training, 66(2), 212-231.

Sjöberg, D., Karp, S., \& Rantatalo, O. (2019). What students who perform in 'secondary roles' can learn from scenario training in vocational education. International Journal for Research in Vocational Education and Training, 6(1), 46-67.

Söderström, T., Lindgren, C., Sjöberg, D., Söderlund, R., Åström, E., \& Widing, M. (2020). The impact of a preparation phase on the development of practical knowledge in police education: A comparison of two conditions for preparing a practical scenario training. Journal of Vocational Education \& Training. https://doi.org/: $10.1080 / 13636820.2020 .1786441$

Stalder, B. E. (2012). School-to-work transitions in apprenticeship-based VET systems: The Swiss approach. In S. Billett, G. Johnson, S. Thomas, C. Sim, S. Hay \& J. Ryan (Eds.), Experience of school transitions (pp. 123-139). Springer.

Ümarik, M., Loogma, K., \& Hinno, K. (2010). Structural decoupling between the VET and the employment systems: Challenges manifested in assessment of practical training. Journal of Education and Work, 23(2), 145-160.

Wheelahan, L. (2015). The future of Australian vocational education qualifications depends on a new social settlement. Journal of Education and Work, 28(2), 126-146.

Wilke, A., \& Magenheim, J. (2017, April). Requirements analysis for the design of workplace-integrated learning scenarios with mobile devices: Mapping the territory for learning in industry 4.0. Paper presented at the IEEE Global Engineering Education Conference, Athens, GR. 
Winch, C. (2013). Three different conceptions of know-how and their relevance to professional and vocational education. Journal of Philosophy of Education, 47(2), 281-298.

Yasak, Z., \& Alias, M. (2017, November). Designing learning materials in TVET:

Application of the learning hierarchy technique. Paper presented at the 9th IEEE International Conference on Engineering Education. Kanazawa, JP. 